\title{
Epidemiology Of Pelvic Ring Fractures and Injuries: A Retrospective Study
}

\author{
Elnara Efendiyeva ${ }^{1 *}$, Assylzhan Messova $^{2}$, Ayan Myssayev $^{3}$, Aidos Tlemissov $^{4}$, Murat Muratoglu $^{5}$, Yersin Zhunussov $^{6}$ \\ ${ }^{1}$ Department of Epidemiology and Biostatistics, Semey Medical University, Semey, Kazakhstan; ${ }^{2}$ Department of Emergency \\ Medicine, Semey Medical University, Semey, Kazakhstan; ${ }^{3}$ Department of Science and Human Resources, Ministry of Health of \\ the Republic of Kazakhstan, Nur-Sultan, Kazakhstan; ${ }^{4}$ Department of Orthopedic Surgery, Semey Medical University, Semey, \\ Kazakhstan; ${ }^{5}$ Department of Emergency Medicine, Faculty of Medicine, Başkent University, Ankara, Turkey; ${ }^{6}$ Department of \\ Orthopedic Surgery, Doctor of Medical Science, Semey Medical University, Semey, Kazakhstan
}

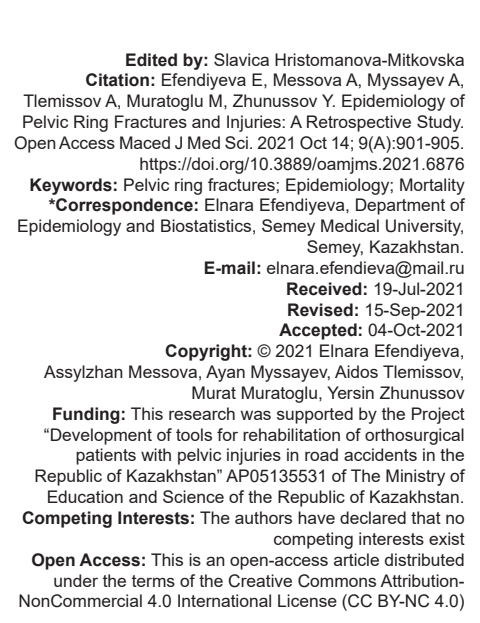

Introduction

Pelvic fractures are a serious medical problem and are often associated with multiple system injuries with high mortality [1], [2], [3]. The incidence of pelvic fractures is relatively small, $16 \%$ of the total number of injuries [4]. Unstable injuries of pelvic rings, accompanied by shock and bleeding result in a significantly worse prognosis [5].

Recent publications have focused on examining the effects of injuries to the pelvic bones, providing emergency care, and various treatment methods [6], [7], [8]. A few publications are devoted to the study of the epidemiology of pelvic injuries, where the authors evaluate the sex and age structure of patients with pelvic injuries [1], [9], [10], the place and mechanism of injury, the anatomical location of injuries, and other indicators [5], [11], [12].

The aim was to study the epidemiology of patients admitted with pelvic fractures at level 1 trauma center of the city of Nur-Sultan of the Republic of Kazakhstan.

\section{Methods}

This study is a descriptive retrospective within a single institution. This work was carried out as part of a grant-financing project of the Ministry of Education and Science of the Republic of Kazakhstan: IRN AP05135531 "Development of tools for rehabilitation of orthosurgical patients with pelvic injuries in road accidents in the Republic of Kazakhstan." The present study protocol was reviewed and approved by the Ethics Committee of Semey State Medical University dated on September 22, 2017. Informed Consent: Informed consent was obtained from patients who participated in this study.

The cross-sectional study design is used. It includes all cases of pelvic injuries $(n=212)$ of the 
patients that were on inpatient treatment in "Nur- Sultan city Hospital No. 1" for the period from January 1, 2014, to December 31, 017. The main source of information was Form No. 027/u: "Extract from the inpatient medical record." The following information was copied for the study: Age, gender (male/female), race (Asian/European), injury mechanism (concealment of the mechanism, road traffic injuries (passenger/ driver), road traffic injuries (motorcycle), fall from own height, a fall from a height of more than $1 \mathrm{~m}$, road traffic injuries (collision with a pedestrian), industrial, domestic (intentional)), place of injury (unknown/city/ village/highway/house, institution, organization), date of arrival (day of the week/season), the affected ring side (right/left/both/symphysis), concomitant injuries, emergency intervention (use of an external fixation device/no intervention), Tile classification of pelvic injuries $(A / B / C)$, treatment (non-surgical/surgical), and its outcomes (recovery/death).

All statistical analyses were performed using SPSS 20.0 program. Descriptive statistics, Chi-square test for nominal data, non-parametric Kruskal-Wallis test for independent samples, and Mann-Whitney $\mathrm{U}$ test were used to describe the data.

\section{Results}

The results were presented in a descriptive manner. 212 cases of pelvic injuries were analyzed, that were on inpatient treatment in level 1 trauma center for the 4-year period.

The mean age of the victims was 34.5 years (95\% confidence interval [Cl] Min 15, Max 80, Me 31. Range 65). The mean age of men was 32.61 years $(95 \%$ Cl 30.52; 34.70; Min 16, Max 71, Me 30. Range 55). The mean age of women was 37.12 years (95\% Cl 33.69; 40.56; Min 15, Max 80, Me 33. Range 65), $p=0.081$.

The male to female ratio was $123 / 89$, with males forming the majority in the study population $(58 \%)$. About $84.4 \%$ of patients $(n=179)$ were Asians and $15.6 \%(n=33)$ were Europeans.

According to the seasons, cases of the pelvic bone injuries were recorded as follows: In the spring of $21.7 \%(n=46)$, in the winter of $17.5 \%(n=37)$, in the summer of $33.0 \%(n=70)$, and in the autumn of $27.8 \%$ $(n=59)$.

The results of the distribution of pelvic injuries among the days of the week were interesting (Table 1).

On Monday $4.2 \%(n=9)$, on Tuesday $-22.2 \%$ of cases $(n=47)$, on Thursday $-26.4 \%$ of cases $(n=56)$ on Friday $-8 \%(n=17)$, on Saturday $-24.5 \%$ of cases $(n=52)$, and on Sunday $5.7 \%(n=12)$.
Table 1: The distribution of pelvic injuries by day of the week

\begin{tabular}{lll}
\hline Day of the week & $\mathrm{n}$ & $\%$ \\
\hline Monday & 9 & 4.2 \\
Tuesday & 47 & 22.2 \\
Wednesday & 19 & 9.0 \\
Thursday & 56 & 26.4 \\
Friday & 17 & 8.0 \\
Saturday & 52 & 24.5 \\
Sunday & 12 & 5.7 \\
Total & 212 & 100.0 \\
\hline
\end{tabular}

The distribution of injuries by the mechanism of injury is presented in Table 2.

Table 2: The distribution of injuries by the mechanism of injury

\begin{tabular}{llll}
\hline No. & Mechanism of injury & $\mathrm{n}$ & $\%$ \\
\hline 0. & Unknown (concealment of mechanism) & 1 & 0.5 \\
1. & Road traffic injuries (total 59.8\%) & 51 & 24.1 \\
& Passenger/driver & 4 & 1.9 \\
& Motorcycle & 70 & 33.3 \\
& Pedestrian collisions & 1 & 0.5 \\
& Railway & & \\
2. & Fall from heights (total 35.4\%) & 12 & 5.7 \\
& Fall from own height & 63 & 29.7 \\
3. & Fall from a height more than 1 m & 8 & 3.8 \\
4. & Occupational injury & 2 & 0.9 \\
& Domestic injury (intentional) & 212 & 100.0 \\
\hline
\end{tabular}

Regarding the mechanism of the pelvic ring injuries, we observed that in $24.1 \%$ of cases $(n=51)$ traffic accidents (passenger/driver) became the cause of pelvic injuries, in $29.7 \%$ of cases $(n=63)$ - a fall from a height of more than $1 \mathrm{~m}$, and in $33.0 \%$ of cases $(n=70)$ - collisions with pedestrians.

About $56.1 \%$ (119) of the patients were injured in urban areas, $34.0 \%$ (72) - in the home/organization or institution, $9 \%$ (19) - on the highway, $0.5 \%$ (1) - in rural areas, and $0.5 \%$ (1) - concealed circumstances and place of injury.

Detailed distribution of the fractures according to the Tile/AO classification is shown in Table 3.

Table 3: Affected ring side and pelvic ring fracture/injury classification (Tile classification)

\begin{tabular}{lll}
\hline Affected ring side & $\mathrm{n}$ & $\%$ \\
\hline Both & 65 & 30.7 \\
Symphysis & 16 & 7.5 \\
Left & 64 & 30.2 \\
Right & 64 & 30.2 \\
Others & 3 & 1.4 \\
Total & 212 & 100.0 \\
\hline Tile/AO Classification & $\mathrm{n}$ & $\%$ \\
\hline Type A & 87 & 41 \\
Type B & 92 & 43.4 \\
Type C & 33 & 15.6 \\
Total & 212 & 100.0 \\
\hline
\end{tabular}

Most of the fractures were Type B - 43.4\% ( $n=92)$, followed by Type A - 41.0\% $(n=87)$.

Treatment outcomes of patients with the pelvic bone injuries, based on the Tile/AO classification, are presented in Figure 1.

The highest recovery rates were observed for type B fractures, but mortality was highest for type C fractures. $p=0.025$.

The average length of hospital stay for men was 18.80 days $(95 \%$ Cl 16.12; 21.49; Min 1, Max 66 , Me 15. Range 65). The average length of hospital 


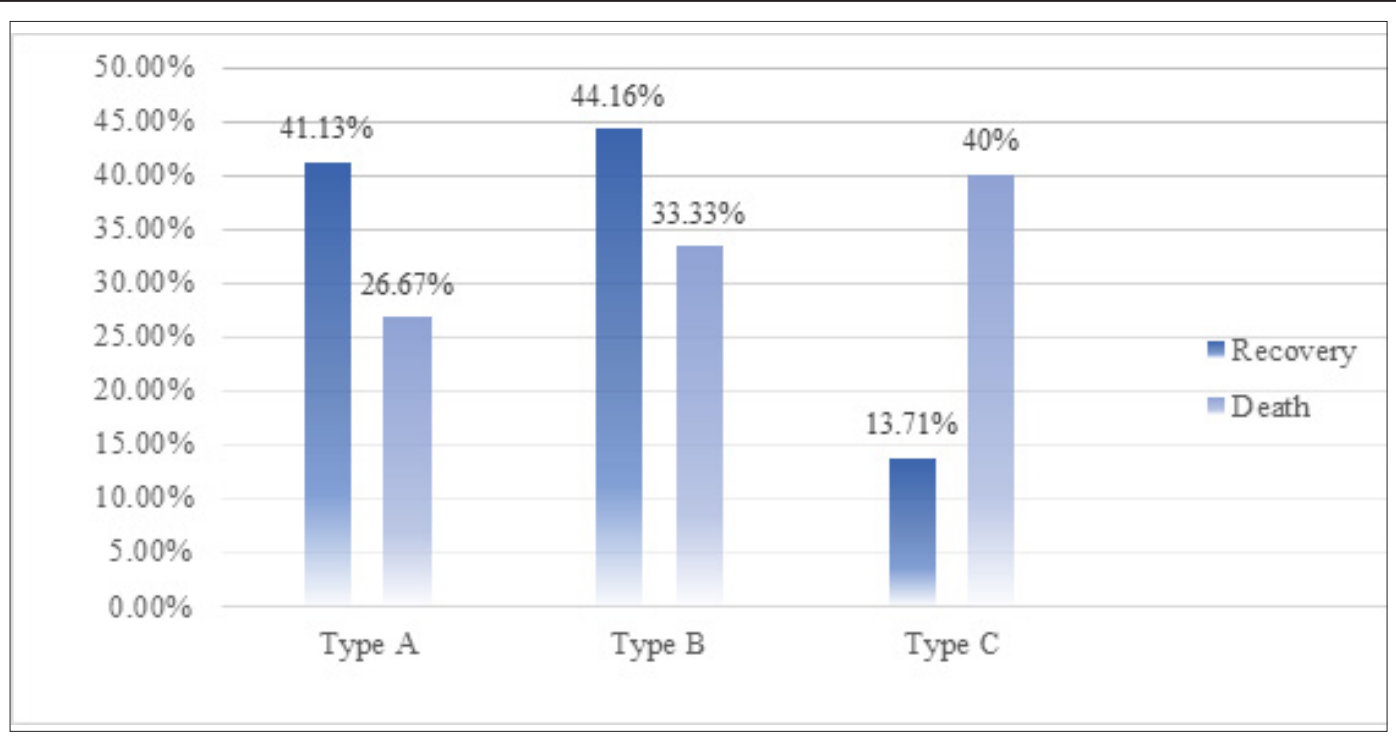

Figure 1: Treatment outcomes of patients with the pelvic fractures, according to Tile/AO classification

stay for women was 18.57 days (95\% Cl 14.99; 22.16; Min 1, Max 106, Me 14. Range 105) $p=0.876$.

The average length of stay in the intensive care unit for men was 1.63 days $(95 \% \mathrm{Cl} 0.83 ; 2.42$; Min 0, Max 32, Me 0. Range 32). The average length of stay in the intensive care unit for women was 1.60 days (95\% Cl 0.29; 2.90; Min 0, Max 42, Me 14. Range 42) $\mathrm{p}=0.115$.

Isolated pelvic fractures were rare. According to Table 4 , it is clear that $92 \%$ of patients with pelvic bone injuries had concomitant injuries. Most common non-orthopedic injuries were head, chest and limb, internal organ injuries (63 cases, 29.7\%).

Table 4: Concomitant injuries

\begin{tabular}{lll}
\hline Concomitant injuries & $\mathrm{n}$ & $\%$ \\
\hline No concomitant injuries & 17 & 8.0 \\
Head injuries & 29 & 13.7 \\
Head injuries, chest and limb injuries & 56 & 26.4 \\
Head injuries, chest and limb injuries, internal organ injuries & 63 & 29.7 \\
Head injuries, chest and limb injuries, internal organ injuries, genitourinary & 3 & 1.4 \\
injuries & & \\
Head injuries, chest and limb injuries, genitourinary injuries & 1 & 0.5 \\
Head injuries, internal organ injuries & 2 & 0.9 \\
Head injuries, internal organ injuries, genitourinary injuries & 1 & 0.5 \\
Chest and limb injuries & 25 & 11.8 \\
Chest and limb injuries, internal organ injuries & 9 & 4.2 \\
Internal organ injuries & 3 & 1.4 \\
Internal organ injuries, genitourinary injuries & 1 & 0.5 \\
Genitourinary injuries & 2 & 0.9 \\
Total & 212 & 100.0 \\
\hline
\end{tabular}

On admission, an external fixation device was applied as an emergency intervention to stabilize the pelvic bones in $64.2 \%(n=136)$ of patients. About $35.4 \%$ $(n=75)$ of patients were admitted without emergency intervention, and one patient $(0.5 \%)$ received emergency surgical treatment of the pelvic bone injuries.

Eighty patients (37.7\%) were managed surgically while 132 (62.3\%) were given conservative treatment.

About $92.9 \%(n=197)$ of the patients were discharged, $7.1 \%(n=15)$ had a fatal outcome (did not need surgical treatment, $p=0.001)$.

\section{Discussion}

Pelvic fractures are more common in patients of the first four decades of life [11]. Thus, the average age of the patients with pelvic bone injuries in our study was 34.5 , which is slightly lower than the average age indicated in retrospective study by Ruatti, aimed to identify pelvic ring anatomical lesions [5], and studies by other authors (37 years and older) [1], [13]. This can be explained by the fact that Nur-Sultan is the capital, where a lot of young people migrate from other regions in search of work.

The predominance of people of Asian ethnicity among the patients is due to the predominance of the indigenous population of the Republic of Kazakhstan. It should be noted that pelvic fractures are subject of men of economically active working age [14]. However, according to some foreign authors, the frequency of fractures among men is $2.73 / 10,000$ (2.48-3.01), among women significantly higher - 5.82/10,000 (5.46-6.20) [9], [10]. There were no significant differences between the ages of affected men and women in our study $(p>0.05)$

It was observed that the largest number of patients with pelvic injuries was recorded in summer and autumn. On Monday and Sunday, the frequency of damage to the pelvic bones was minimal. We associate this with the work schedule of the victims. Nonetheless, no references in the literature regarding these parameters were retrieved.

The most common mode of injury was road traffic injuries comprising $59.8 \%$ of the cases (Table 2), falls from heights were $35.4 \%$. Similar data are presented in foreign publications [15]. According to Chueire et al., traffic accidents caused pelvic injuries in $58 \%$ of cases, and high mortality due to falls from a height was observed (18\%) [4], [16], [17]. Falls from a 
height of more than $1 \mathrm{~m}$ occurred in $6 \%$ of cases in one of the studies, which is much less than in our study [13]. We believe that this is due to the active construction work in the capital. Compliance with traffic regulations as well as strict observance of safety measures in construction are the need of the hour.

It should be noted that in our study there were no significant differences between the mechanism of injury and the age of the victims ( $p>0.05$ ), as well as the length of stay in the intensive care unit $(p>0.05)$. However, there was a statistically significant difference between the mechanism of the pelvic bone injuries and the length of hospitalization $\left({ }^{*} p<0.05\right)$. The urban zone was the most frequent place where the injuries occurred which is consistent with other studies [13].

We observed that both sides of the ring were affected equally. The rarest but most prognostically unfavorable was type $\mathrm{C}$ fractures (Table 3 ). Foreign data also indicate a higher frequency types $A$ and $B$ pelvic fractures according to the Tile/AO classification [11].

In our study, an external fixation device was applied to stabilize the pelvic bones in $64.2 \%(n=136)$ of patients. About $35.4 \%(n=75)$ of patients were admitted without emergency intervention, and one patient $(0.5 \%)$ received emergency surgical treatment of the pelvic bone injuries, whereas according to Damasceno et al., only $16.6 \%$ ( $n=11$ ) needed emergency fixation. We associate such differences with a small sample size of their study (66 people) [13].

The average length of hospital stay was 18.71 days. The average length of stay in the intensive care unit was 1.61 days, which does not contradict foreign publications [1], [10]. It should be noted that there were no statistically significant differences in the above indicators between men and women $(p=0.876$ and $p=0.115$, respectively)

The direct result of high-energy trauma is a high frequency of multiple lesions (92\%), which affect patient prognosis. Foreign sources give us slightly fewer data. In a study by Gomes et al., only $54 \%$ of patients with pelvic bone injuries had concomitant injuries [17]. At the same time, $15 \%$ of them needed exploratory laparotomy [17], whereas in our study it was performed only on 1 patient $(0.5 \%)$. Pereira et al. indicated that $42.4 \%$ of patients with pelvic ring injuries had concomitant injuries [13].

It can be noted that a combination with a head injury (Table 4 ) occurred in $13.7 \%$ of cases $(n=29)$, with head, chest, and limb injuries together - in $26.4 \%$ of cases ( $n=56)$, with head, chest, and limbs, and internal organ injuries - in $29.7 \%$ of cases $(n=63)$. In a similar study, Giannoudis et al. noted a combination of the pelvic bone injuries with a head injury in $16.9 \%$ of patients, with chest injuries in $21.2 \%$ of the patients, which does not contradict our data [18].

In the present study, fatal outcome was recorded in $7.1 \%$ of victims $(n=15)$ admitted to hospital treatment. Type $\mathrm{C}$ pelvic injury was significantly more likely to cause death, as shown in Figure 1 ( $\left.{ }^{*} p<0.05\right)$. And in patients with surgical treatment of pelvic ring injury, there were no fatal outcomes $(p=0.001)$. Similar indicators were reflected in the publications of Balogh et al., where hospital mortality was about $10 \%$ [19], [20]. Foreign data also confirm that type $\mathrm{C}$ pelvic injury is a predictor of fatal outcome [3], [4].

We believe that present study gives an idea about demographic factors and causes of pelvic fractures in Kazakhstan. Unfortunately, there is no unified trauma registry that would simplify the collection of data for retrospective studies in the Republic of Kazakhstan. For further investigation a unified trauma registry should be established.

\section{Conclusions}

Based on the results of this study, the following conclusions can be made: Pelvic injuries prevail in males; the greatest number of injuries was recorded in summer and autumn; road traffic accidents, falls from a height occupy a leading place among the causes of pelvic injuries; most injuries do not need emergency intervention; non-surgical treatment is the most common; in cases treated surgically, external fixation device was used as an emergency intervention. About $92 \%$ of patients with pelvic bone injuries had concomitant injuries. Type $\mathrm{C}$ pelvic injury was significantly more likely to cause fatal outcome.

\section{Authors Contributions}

Conceptualization: Zhunussov ET. Data
curation: $\begin{gathered}\text { Efendiyeva } \\ \text { El. }\end{gathered}$
analysis: Efendiyeva El, Messova AM. Methodology:
Efendiyeva El., Messova AM., Myssayev AO,
Zhunussov ET, Tlemissov AS, Murat
Muratoglu. Validation: Efendiyeva El. Investigation:
Efendiyeva El., Myssayev AO. Writing original draft:
Efendiyeva El. Writing-review and editing Messova AM.,
Zhunussov ET.

\section{References}

1. Ghosh S, Aggarwal S, Kumar V, Patel S, Kumar P. Epidemiology of pelvic fractures in adults: Our experience at a tertiary hospital. 
Chin J Traumatol. 2019;22(3):138-41. https://doi.org/10.1016/j. cjtee.2019.03.003

\section{PMid:31056468}

2. Lee MJ, Wright A, Cline M, Mazza MB, Alves T, Chong S. Pelvic fractures and associated genitourinary and vascular injuries: A multisystem review of pelvic trauma. AJR Am J Roentgenol. 2019;213(6):1297-306. https://doi.org/10.2214/ajr.18.21050 PMid:31613662

3. Martínez F, Alegret N, Carol F, Laso MJ, Zancajo J, García E, et al. Pelvic fracture in the patient with multiple injuries: Factors and lesions associated with mortality. Emergencias. 2018;30(2):91-7.

PMid:29547231

4. Palmcrantz J, Hardcastle TC, Naidoo SR, Muckart DJ, Ahlm K, Eriksson A. Pelvic fractures at a new level 1 trauma centre: Who dies from pelvic trauma? The Inkosi Albert Luthuli central hospital experience. Orthop Surg. 2012;4(4):216-21. https://doi. org/10.1111/os.12002

PMid:23109305

5. Ruatti S, Guillot S, Brun J, Thony F, Bouzat P, Payen JF, et al. Which pelvic ring fractures are potentially lethal? Injury. 2015;46(6):1059-63. https://doi.org/10.1016/j. injury.2015.01.041

PMid:25769199

6. Rommens PM, Wagner D, Hofmann A. Minimal invasive surgical treatment of fragility fractures of the pelvis. Chirurgia (Bucur). 2017;112(5):524-37. https://doi.org/10.21614/ chirurgia.112.5.524

PMid:29088552

7. Gary JL, Kumaravel M, Gates K, Burgess AR, Routt ML, Welch T, et al. Imaging comparison of pelvic ring disruption and injury reduction with use of the junctional emergency treatment tool for preinjury and postinjury pelvic dimensions: A cadaveric study with computed tomography. J Spec Oper Med. 2014;14(4):30-4. PMid:25399365

8. Esmer E, Esmer E, Derst $P$, Schulz $M$, Siekmann $H$, Delank KS, et al. Influence of external pelvic stabilization on hemodynamically unstable pelvic fractures. Unfallchirurg. 2017;120(4):312-9. https://doi.org/10.1007/s00113-015-0119-3 PMid:26676631

9. Nanninga GL, de leur K, Panneman MJ, van der Elst $M$, Hartholt KA. Increasing rates of pelvic fractures among older adults: The Netherlands, 1986-2011. Age Ageing. 2014;43(5):648-53. https://doi.org/10.1093/ageing/aft212 PMid:24419459

10. Yang NP, Chan CL, Chu D, Lin YZ, Lin KB, Yu CS, et al. Epidemiology of hospitalized traumatic pelvic fractures and their combined injuries in Taiwan: 2000-2011 National health insurance data surveillance. Biomed Res Int. 2014;2014:878601. https://doi.org/10.1155/2014/878601 PMid:24804258

11. Andrich S, Haastert B, Neuhaus E, Neidert K, Arend W,
Ohmann C, et al. Epidemiology of pelvic fractures in Germany: Considerably high incidence rates among older people. PLoS One. 2015;10(9):e0139078. https://doi.org/10.1371/journal. pone. 0139078

PMid:26418971

12. Wang ZH, Li KN. Regional injury classification and treatment of open pelvic fractures. Orthop Surg. 2019;11(6):1064-71. https:// doi.org/10.1111/os.12554

PMid:31733038

13. Pereira GJ, Damasceno ER, Dinhane DI, Bueno FM, Leite JB da Costa Ancheschi B. Epidemiology of pelvic ring fractures and injuries. Rev Bras Ortop. 2017;52(3):260-9. https://doi. org/10.1016/j.rboe.2017.05.012

PMid:28702382

14. Saydam M, Şahin M, Yilmaz KB, Tamam S, Ünlü G, Atilla H, et al. Correlation of pelvic fractures and associated injuries: An analysis of 471 pelvic trauma patients. Ulus Travma Acil Cerrahi Derg. 2019;25(5):489-96. https://doi.org/10.5505/ tjtes.2018.72505

PMid:31475332

15. Agri $F$, Bourgeat $M$, Becce $F$, Moerenhout $K$, Pasquier $M$, Borens $\mathrm{O}$, et al. Association of pelvic fracture patterns, pelvic binder use and arterial angio-embolization with transfusion requirements and mortality rates; a 7-year retrospective cohort study. BMC Surg. 2017;17(1):104. https://doi.org/10.1186/ s12893-017-0299-6

PMid:29121893

16. Davarinos N, Ellanti P, Morris S, Mc Elwain JP. Epidemiology of pelvic and acetabular trauma in a Dublin tertiary hospital: A 10-year experience. Ir J Med Sci. 2012;181(2):243-6. https:// doi.org/10.1007/s11845-011-0791-4

PMid:22207476

17. Chueire AG, Filho GC, Santos AF, Pockel KP. Fraturas do anel pélvico:Estudoepidemiológico.Acta OrtopBras. 2004;12(1):5-11. https://doi.org/10.1590/s1413-78522004000100001

18. Giannoudis PV, Grotz MR, Tzioupis C, Dinopoulos H, Wells GE, Bouamra $\mathrm{O}$, et al. Prevalence of pelvic fractures, associated Injuries, and mortality: The United Kingdom perspective. J Trauma. 2007;63(4):875-83. https://doi.org/10.1097/01. ta.0000242259.67486.15

PMid: 18090020

19. Balogh Z, King KL, Mackay P, McDougall D, Mackenzie S, Evans JA, et al. The epidemiology of pelvic ring fractures: A population-based study. J Trauma. 2007;63(5):1066- 73; discussion 1072-3. https://doi.org/10.1097/ ta.0b013e3181589fa4

PMid:17993952

20. Hermans E, Biert J, Edwards MJ. Epidemiology of pelvic ring fractures in a level 1 trauma Center in the Netherlands. Hip Pelvis. 2017;29(4):253-61. https://doi.org/10.5371/ hp.2017.29.4.253

PMid:29250500 